Article

\title{
Does Whistleblowing Work for Air Pollution Control in China? A Study Based on Three-party Evolutionary Game Model under Incomplete Information
}

\author{
Yunpeng Yang ${ }^{+}(\mathbb{D}$ and Weixin Yang $*,+(\mathbb{D}$ \\ Business School, University of Shanghai for Science and Technology, Shanghai 200093, China; \\ yang_yunpeng@outlook.com \\ * Correspondence: iamywx@outlook.com; Tel.: +86-21-5596-0082 \\ + Yunpeng Yang and Weixin Yang are joint first authors. They contributed equally to this paper.
}

Received: 21 November 2018; Accepted: 7 January 2019; Published: 10 January 2019

check for updates

\begin{abstract}
During China's air pollution campaign, whistleblowing has become an important way for the central government to discover local environmental issues. The three parties involved in whistleblowing are: the central government environmental protection departments, the local government officials, and the whistleblowers. Based on these players, this paper has constructed an Evolutionary Game Model under incomplete information and introduced the expected return as well as replicator dynamics equations of various game agents based on analysis of the game agents, assumptions, and payoff functions of the model in order to study the strategic dynamic trend and stability of the evolutionary game model. Furthermore, this paper has conducted simulation experiments on the evolution of game agents' behaviors by combining the constraints and replicator dynamics equations. The conclusions are: the central environmental protection departments are able to effectively improve the environmental awareness of local government officials by measures such as strengthening punishment on local governments that do not pay attention to pollution issues and lowering the cost of whistleblowing, thus nurturing a good governance and virtuous circle among the central environmental protection departments, local government officials, and whistleblowers. Based on the study above, this paper has provided policy recommendations in the conclusion.
\end{abstract}

Keywords: whistleblowing; air pollution; evolutionary game; environmental supervision

\section{Introduction}

The Chinese economy has maintained rapid growth since the reform and opening up in 1978. However, along with rapid growth, environmental issues such as air pollution have become increasingly prominent, seriously threatening the urban environment and quality of life [1-4]. In order to control air pollution, China has taken various measures [5-8], in which whistleblowing is a pollution control measure with Chinese characteristics [9].

On 5 June 2009, China's Ministry of Environmental Protection officially launched the "010-12369" hotline for environment-related whistleblowing, which is open to people all over the country, and accepts complaints about all kinds of environmental issues [10]. Based on that, the Ministry of Environmental Protection launched smartphone APPs such as the "Green Knight" Environmental Snapshot in 2014 [11], and further launched the "12369 Environment Whistleblowing Platform" on WeChat in June 2015, the most widely used smartphone social media app in China [12], and completed the integration of all whistleblowing databases nationwide by the end of 2016 to form China's "12369 Integrated Environmental Whistleblowing Management Platform" [13]. This platform has integrated whistleblowing from various channels including the "12369" hotline, WeChat, and 
online platforms at four levels (nation-level, province-level, city-level and county-level), and has enabled interconnection and information sharing among all these four levels [14]. This platform has helped whistleblowing to become one important channel for the central environmental protection department to discover local environmental issues [15].

In 2017, China's Ministry of Environmental Protection's national environmental whistleblowing management platform received 618,856 whistleblowing reports in total, of which 409,548 were reported through the "12369" hotline (accounting for $66.18 \%$ of the total reports), 129,423 were reported on WeChat (accounting for $20.91 \%$ of the total reports), and 79,885 were reported online (accounting for $12.91 \%$ of the total reports) [16]. It can be seen that hotlines and WeChat are two major sources of whistleblowing, accounting for $87.09 \%$ in total. In terms of the whistleblowing from hotlines, most whistleblowing reports were from the eastern and central provinces and municipalities of China, including Jiangsu, Chongqing, Shanghai, Beijing, Liaoning, and Hainan. In terms of whistleblowing on WeChat, the number of whistleblowing reports increased by $96.4 \%$ in 2017 on a year-on-year basis, and the top five provinces in terms of number of whistleblowing reports are: Guangdong, Henan, Shandong, Jiangsu, and Hebei, accounting for around $48 \%$ of the total whistleblowing reports nationwide (see Figure 1) [16].

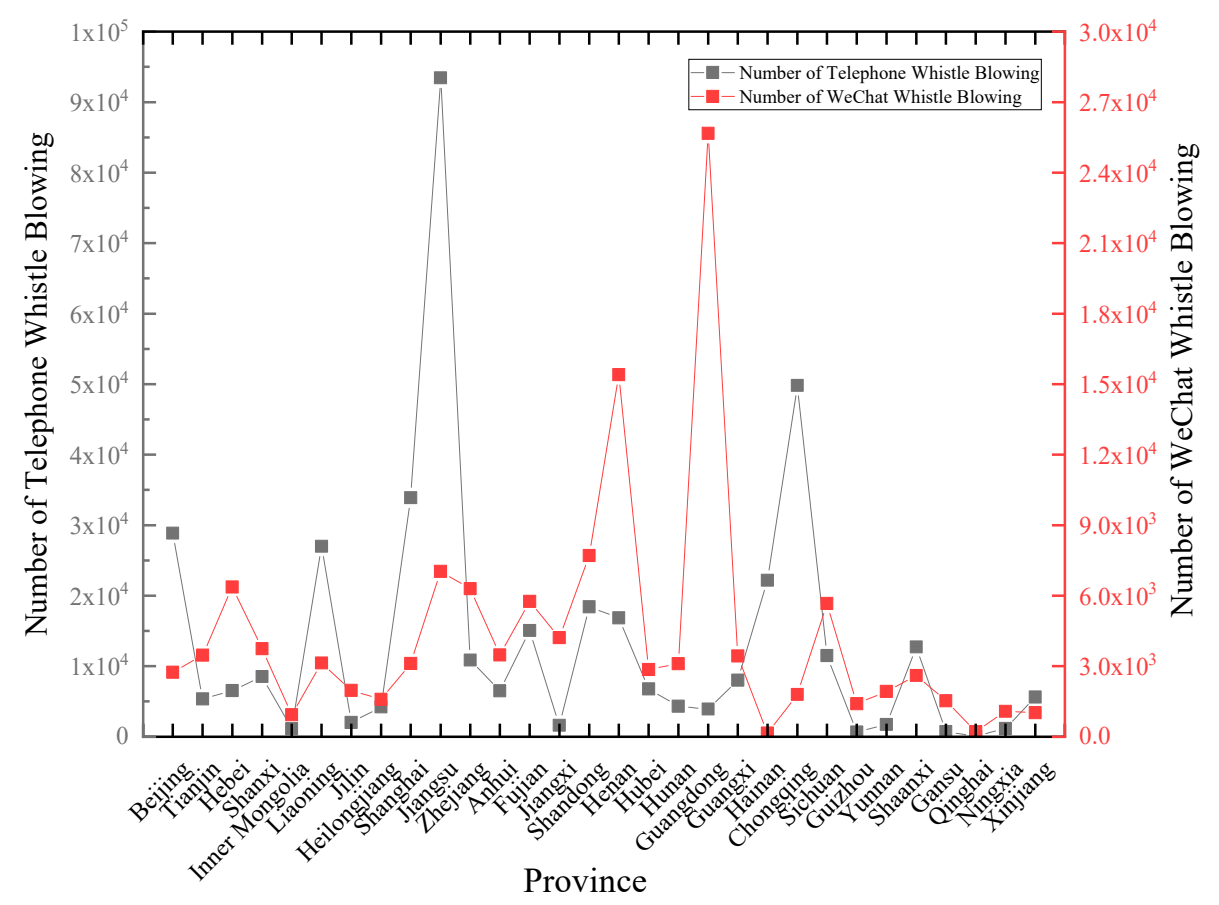

Figure 1. Number of environmental whistleblowing in different provinces of China in 2017, through "12369" Hotline and WeChat.

As seen from the type of pollution in whistleblowing, air pollution is the most prominent, accounting for around $56.7 \%$ in all pollution cases [16], which is also the study subject of this paper. In the process of air pollution whistleblowing, there are three main players involved: the central environmental protection department (the Ministry of Environmental Protection), the local government (official), and the whistleblower (including citizens, enterprises, and other organizations). According to the "Environmental Protection Law of the People's Republic of China", the central environmental protection department can directly penalize the local government if the complaint is verified [9]. Whether from an economic perspective or from the evaluation and career development perspective of local officials, the local governments try their best to minimize the number of whistleblowing [17-19]. On the other hand, although the whistleblowers are rewarded after the complaint is verified [20-22], in practice, they are often harassed in real life and their rights and interests are often violated [23,24], 
which to some extent demotivates the act of whistleblowing. In this case, the central environmental protection department, the local government, and the whistleblower constitute an evolutionary game under incomplete information [25-27].

The academic community has applied the evolutionary game model to environmental protection research and made great progress. For example, Liu et al. (2015) developed an evolutionary game model of two enterprise populations' dynamics and stability for decision-making. By building a system dynamics model, they simulated the aforementioned game and found that the initial choice of strategy was essential to the final result. They concluded that it is important to check the saddle point and external factors [28]. Zhao et al. (2016) established an evolutionary game model to investigate the responses of enterprises to carbon-reduction policies. They examined the individual and combined intervention of carbon-reduction policies through analysis of two scenarios in the simulation based on the game model. They concluded that the combination of these two policies was more efficient than an individual one [29]. Based on the game between the government and enterprises in the context of a complex network, Wu et al. (2017) built an evolutionary model for low-carbon strategies research. By introducing government policy encouragement in the decision-making process of companies, they argued that enterprises' expectations of government encouragement determined whether low-carbon strategies could be diffused. They also concluded that those enterprises quickly adjusting their expectations in the game learned to adopt and follow effective low-carbon strategies [30]. Li et al. (2017) founded a tripartite evolutionary game model based on the relationships among the central and local governments, and land-lost farmers, to analyze China's land expropriation during the rapid urbanization process. They found that serious asymmetry of information between stakeholders led to the low efficiency of the game by simulation analysis. Moreover, they established the reference for the central and local governments to reduce conflicts during land expropriation [31]. Chen (2017) established a three-stage evolutionary game model of the ecological industry chain and achieved the stable strategies by analyzing the equilibrium points of replicator dynamics equations. The author also constructed a multi-agent model to analyze evolutionary paths and trends. Finally, the case of Poyang Lake was used to examine the evolutionary game method [32]. Zhang and Li (2018) built an evolutionary game model of haze cooperative control between governments. They analyzed the dynamic evolution path and stable strategy of this game. Their results showed that the stable state of cooperation cannot be formed between governments spontaneously because of the heterogeneity. Hence the superior government should use administrative penalties to promote the stability of cooperation [33].

However, there are still few studies analyzing environment-related whistleblowing by the evolutionary game method, especially the Three-party Evolutionary Game Model under incomplete information. In order to fill in the blank spaces in game studies on environment-related whistleblowing, this paper has constructed an evolutionary game model under incomplete information that involves the central environmental protection department, the local government, and the whistleblower. In the following parts of this paper, Section 2 introduces the three-party evolutionary game model and conducts detailed analysis on the game agents, assumptions, and payoff functions of the model. Based on the three-party evolutionary game model, Section 3 introduces the expected return and replicator dynamics equations of the three parties in order to perform equilibrium analysis on the game model. Section 4 conducts simulation experiments on the evolution of game agents' behaviors by combining the constraints and replicator dynamics equations and analyzes the impact of changes in parameters on the final evolution result. Section 5 provides conclusions as well as policy recommendations. 


\section{Methods}

\subsection{Game Agent Analysis and Assumptions}

According to China's current laws and regulations and administrative governance structure, the players, and their relationships in this three-party evolutionary game model, are as follows:

(1) Overall relationship: Currently in China, the local government is responsible for air pollution control and governance in different regions of the country under a centralized environmental regulation $[9,34]$. The enterprises that release pollution into the air during production and operation are required to declare the types, quantities, concentrations, emission destinations, and emission methods of their pollutants to the local government. The local government is responsible for pollution control and law enforcement [35], while as the highest regulatory authority for air pollution in China, the Ministry of Environmental Protection oversees and manages air pollution control and governance by local governments at all levels and directly accepts air pollution whistleblowing through hotlines, WeChat, and online platforms [36]. According to common practice in academia [37-41], and also because the local governments at all levels in China generally have the same benefits and costs when they are supervised by the central environmental protection department [42-46], this paper has made "the local government" one single player in the three-party evolutionary game model, and does not distinguish local governments by their administrative levels in China (i.e., province-level, city-level, county-level, district-level, etc.).

(2) The Ministry of Environmental Protection as the central supervision department for environmental protection: The Ministry of Environmental Protection is the highest environmental protection regulator in the country [9]. It analyzes and supervises environmental whistleblowing throughout the country. It passes on whistleblowing cases to relevant local governments to verify and solve problems. It also supervises and handles the issues reported in media or by the public, or problems not properly handled by the local governments [9,36]. Due to limitations in monitoring technology and staffing, it is very difficult for the central environmental supervision department to implement strict all-round supervision throughout the country, and the supervision sometimes fails [18,47-49]. Therefore, the central environmental supervision department's behavior strategy space is (Strict Supervision, Loose Supervision).

(3) The local governments: The behavior pattern of the local governments has two sides. On the one hand, due to the need for political achievement and promotion, local governments consider that "excessive" air pollution control will affect the development of local enterprises as well as local GDP growth and their political achievement, and therefore take a negative attitude and a position of inaction towards air pollution [50-52], and even conduct extreme acts, such as retaliation, against air pollution whistleblowers [53]. On the other hand, air pollution has not only received great emphasis from the central government, it has also caused great damage to the local environment. It threatens the local ecological environment and sustainable development in the long term, and causes irreparable damage to the physical and mental health of local residents, which also motivates the local governments to emphasize and control air pollution to a certain extent [54-56]. The local governments' behavioral strategy space is (Put Emphasis on Pollution Control, Neglect Pollution Control).

(4) The whistleblower: The whistleblowers include the public, the media, and non-governmental environmental protection organizations, etc., who are the direct victims of air pollution. From the perspective of air pollution hazards, the whistleblowers are all affected by air pollution in the long term, and with their increasing environmental awareness and legal awareness, the public will become more and more active in participation in supervision. The whistleblowers can report air pollution issues by reporting, petitioning, exposure, litigation, and claims in order to protect their rights and interests $[10,12,35]$. However, the whistleblowers may also give up on whistleblowing due to the time and effort it costs to collect evidence and proof, the complicated process for supervision and implementation after whistleblowing, the possibilities of retaliation from the local government, etc. [53]. Therefore, the whistleblower's behavioral strategy space is (Blow the Whistle, Not Blow the Whistle). 
Based on the analysis above, it can be seen that there is a game relation among the three parties: the central environmental protection department, the local government, and the whistleblower. This paper has made the following assumptions regarding the three-party evolutionary game model:

Assumption 1. For the central environmental protection department, suppose that the proportion of the central environmental protection department selecting Strict Regulation strategy is $x(0<x<1)$; then the proportion selecting Loose Regulation strategy is $1-x$. The central environmental protection department's pay-off is constant at $R_{1}$, whether it pursues strict regulation or not. If it pursues strict regulation, the regulation cost is $C_{1}$, and the long-term improved social welfare will be $W$ (including reduced air pollution and better health). However, strict regulation would restrict the local economic development, resulting in a loss of $L_{1}$ due to GDP growth slow-down. If the central environmental protection department does not pursue strict regulation, its regulation cost would be $C_{11}\left(C_{1}>C_{11}\right)$, and there will not be any long-term social welfare improvement.

Assumption 2. For local governments, suppose that the proportion of local governments selecting Put Emphasis on Pollution Control strategy is $y(0<y<1)$; then the proportion selecting Neglect Pollution strategy is $1-y$. If they put emphasis on environmental issues and pollution control, their pay-off would be $R_{2}$ (such as reputation and public opinion that would help their promotion), while the cost would be $C_{2}$ (including time cost, economic cost, and loss in GDP growth). If the local officials neglect environmental protection, their short-term pay-off would be $G$ (including short-term GDP growth), while the cost would be $C_{22}\left(C_{2}>C_{22}\right)$. However, if they do not make efforts on pollution control, they would face a penalty of $L_{2}$ if this is discovered by the central environmental protection department, whether through inspections or whistleblowing.

Assumption 3. For the whistleblowers, suppose that the proportion of the whistleblowers selecting Blow the Whistle strategy is $z(0<z<1)$; then the proportion selecting Not Blow the Whistle strategy is $1-z$. The cost of whistleblowing is $C_{3}$. If the central environmental protection department pursues strict regulation, the whistleblower would get a reward of $R_{3}$ from the central environmental protection department as well as a compensation of $R_{33}$ from the local government. However, if the central environmental protection department does not pursue strict regulation, the local government would call off the whistleblowing with a bribery of $R_{333}$. Furthermore, the whistleblower would suffer a loss of $L_{3}$ due to the harms of environmental pollution.

Assumption 4. According to the experience since China's reform and opening up, the air pollution issue is becoming increasingly serious with the rapid economic development. In order to achieve effective environmental protection, this paper assumes that the three-party game system should adopt a mixed strategy of strict supervision by the central environmental department, emphasis on pollution control by the local governments, and active participation and reporting by the whistleblowers.

The parameters and variable descriptions of our model are listed in Table 1.

Table 1. Model parameters and variable descriptions.

\begin{tabular}{|c|c|}
\hline Parameter & Description \\
\hline$R_{1}$ & $\begin{array}{l}\text { The normal income of the central environmental protection department (wage income from } \\
\text { government finance, which is the same under strict regulation and loose regulation) }\end{array}$ \\
\hline$C_{1}$ & The regulation cost of the central environmental protection department under strict regulation \\
\hline$W$ & $\begin{array}{l}\text { The social welfare improvements achieved by the central environmental protection } \\
\text { department's strict regulation }\end{array}$ \\
\hline$L_{1}$ & $\begin{array}{l}\text { The impact of strict regulations on local economic growth (losses including decline in } \\
\text { GDP growth) }\end{array}$ \\
\hline$C_{11}$ & $\begin{array}{l}\text { The regulation cost of the central environmental protection department under loose regulation } \\
\left(C_{1}>C_{11}\right)\end{array}$ \\
\hline$R_{2}$ & $\begin{array}{l}\text { The reputation and public opinion gain of local government officials if they put the emphasis } \\
\text { on environmental issues }\end{array}$ \\
\hline
\end{tabular}


Table 1. Cont.

\begin{tabular}{|c|c|}
\hline Parameter & Description \\
\hline $\mathrm{C}_{2}$ & $\begin{array}{l}\text { Cost of local government officials if they work on environmental issues (including economic } \\
\text { cost and time cost of pollution control) }\end{array}$ \\
\hline G & $\begin{array}{l}\text { The short-term gain of local government officials if they neglect environmental issues (such as } \\
\text { short-term growth of local GDP) }\end{array}$ \\
\hline$C_{22}$ & The cost to local government officials if they neglect environmental issues $\left(C_{2}>C_{22}\right)$ \\
\hline$L_{2}$ & $\begin{array}{l}\text { The penalty on local government officials if they neglect environmental issues (if discovered } \\
\text { by inspections or due to whistleblowing) }\end{array}$ \\
\hline$R_{3}$ & $\begin{array}{l}\text { The rewards to the whistleblower by the central environmental protection department if it } \\
\text { pursues strict regulation }\end{array}$ \\
\hline$C_{3}$ & The cost of whistleblowing \\
\hline$R_{33}$ & $\begin{array}{l}\text { The compensation to the whistleblower by the local government if the central environmental } \\
\text { protection department pursues strict regulation }\end{array}$ \\
\hline$R_{333}$ & $\begin{array}{l}\text { The cost to call off whistleblowing paid by the local government (such as "hush money") if the } \\
\text { central environmental protection department does not pursue strict regulation and the local } \\
\text { government neglects pollution issues }\end{array}$ \\
\hline$L_{3}$ & $\begin{array}{l}\text { The loss suffered by the whistleblower due to environmental pollution when the local } \\
\text { government officials neglect pollution issues }\end{array}$ \\
\hline
\end{tabular}

\subsection{The Payoff Function}

Since the payoff of each game agent is affected by the strategy of the other two game agents, there are eight strategy combinations for the evolutionary game between the central environmental department (a), local government officials (b), and whistleblowers (c), as below (see Figure 2): ( $a_{1}$ Strict Regulation, $b_{1}$ Put Emphasis on Pollution Control, $c_{1}$ Blow the Whistle); ( $a_{2}$ Strict Regulation, $\mathrm{b}_{2}$ Neglect Pollution Control, $\mathrm{c}_{2}$ Blow the Whistle); ( $\mathrm{a}_{3}$ Loose Regulation, $\mathrm{b}_{3}$ Put Emphasis on Pollution Control, $c_{3}$ Blow the Whistle); ( $a_{4}$ Loose Regulation, $b_{4}$ Neglect Pollution Control, $c_{4}$ Blow the Whistle); ( $a_{5}$ Strict Regulation, $b_{5}$ Put Emphasis on Pollution Control, $c_{5}$ Not Blow the Whistle); ( $a_{6}$ Strict Regulation, $b_{6}$ Neglect Pollution Control, $c_{6}$ Not Blow the Whistle); ( $a_{7}$ Loose Regulation, $b_{7}$ Put Emphasis on Pollution Control, $c_{7}$ Not Blow the Whistle); ( $a_{8}$ Loose Regulation, $b_{8}$ Neglect Pollution Control, $\mathrm{c}_{8}$ Not Blow the Whistle).

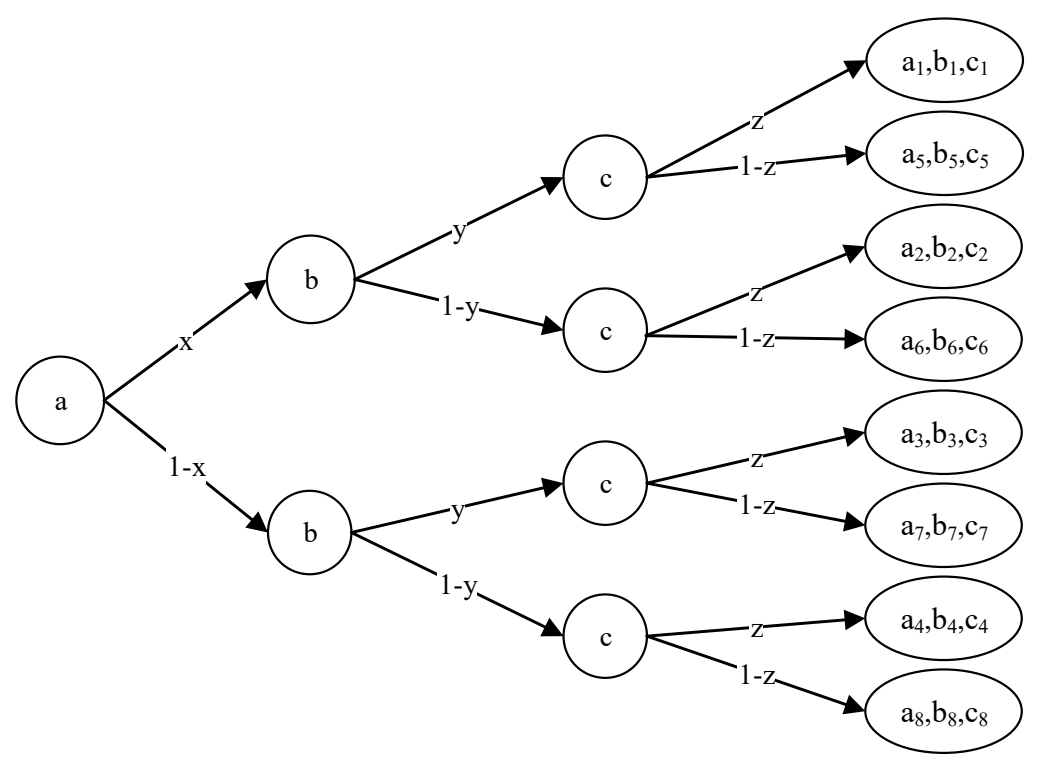

Figure 2. Three-party evolutionary game flow chart. 
When the strategy of the central environmental department, local government officials, and whistleblowers is ( $a_{1}$ Strict Regulation, $b_{1}$ Put Emphasis on Pollution Control, $c_{1}$ Blow the Whistle), the central environmental protection department's pay-off is constant at $R_{1}$, and the regulation cost is $C_{1}$, and the long-term improved social welfare will be W. However, strict regulation would restrict local economic development, resulting in a loss of $L_{1}$ due to GDP growth slow-down. The local governments' pay-off would be $R_{2}$, while the cost would be $C_{2}$. The whistleblower would get a reward of $R_{3}$ from the central environmental protection department, and the cost of whistleblowing would be $C_{3}$. Similarly, the benefits of the central environmental department, local government officials, and whistleblowers under other strategic combinations can be derived. (see Table 2).

Table 2. The Payoff matrix of the three-party evolutionary game.

\begin{tabular}{|c|c|c|c|c|c|}
\hline \multirow{2}{*}{\multicolumn{2}{|c|}{$\begin{array}{c}\text { Central Environmental Protection Department: a } \\
\text { Local Government Officials: } b\end{array}$}} & \multicolumn{2}{|c|}{ Strict Regulation $(x)$} & \multicolumn{2}{|c|}{ Loose Regulation $(1-x)$} \\
\hline & & $\begin{array}{c}\begin{array}{c}\text { Put Emphasis on } \\
\text { Pollution Control }(y)\end{array} \\
\left(\mathrm{a}_{1}, \mathrm{~b}_{1}, \mathrm{c}_{1}\right) \\
\left(\mathrm{a}_{5}, \mathrm{~b}_{5}, \mathrm{c}_{5}\right)\end{array}$ & $\begin{array}{l}\begin{array}{c}\text { Neglect Pollution } \\
\text { Control }(1-y) \\
\left(\mathrm{a}_{2}, \mathrm{~b}_{2}, \mathrm{c}_{2}\right) \\
\left(\mathrm{a}_{6}, \mathrm{~b}_{6}, \mathrm{c}_{6}\right)\end{array}\end{array}$ & $\begin{array}{c}\begin{array}{c}\text { Put Emphasis on } \\
\text { Pollution Control }(y)\end{array} \\
\left(a_{3}, b_{3}, c_{3}\right) \\
\left(a_{7}, b_{7}, c_{7}\right)\end{array}$ & $\begin{array}{c}\begin{array}{c}\text { Neglect Pollution } \\
\text { Control }(1-y)\end{array} \\
\left(a_{4}, b_{4}, c_{4}\right) \\
\left(a_{8}, b_{8}, c_{8}\right)\end{array}$ \\
\hline
\end{tabular}

Based on assumptions in Section 2.1, the payoffs of the different game agents under different strategy combinations can be written as follows:

$$
\begin{gathered}
a_{1}=W+R_{1}-L_{1}-C_{1}-R_{3} ; b_{1}=R_{2}-C_{2} ; c_{1}=R_{3}-C_{3} ; \\
a_{2}=W+R_{1}-L_{1}-C_{1}-R_{3}+L_{2} ; b_{2}=G-C_{22}-L_{2}-R_{33} ; c_{2}=R_{3}-C_{3}+R_{33}-L_{3} ; \\
a_{3}=R_{1}-C_{11} ; b_{3}=R_{2}-C_{2} ; c_{3}=-C_{3} ; \\
a_{4}=R_{1}-C_{11}+L_{2} ; b_{4}=G-C_{22}-L_{2}-R_{333} ; c_{4}=-C_{3}+R_{333}-L_{3} ; \\
a_{5}=W+R_{1}-L_{1}-C_{1} ; b_{5}=R_{2}-C_{2} ; c_{5}=0 ; \\
a_{6}=W+R_{1}-L_{1}-C_{1}+L_{2} ; b_{6}=G-C_{22}-L_{2}-R_{33} ; c_{6}=R_{3}-L_{3} ; \\
a_{7}=R_{1}-C_{11} ; b_{7}=R_{2}-C_{2} ; c_{7}=0 ; \\
a_{8}=R_{1}-C_{11} ; b_{8}=G-C_{22} ; c_{8}=-L_{3}
\end{gathered}
$$

\section{Equilibrium Analysis}

\subsection{The Expected Payoff and Replicator Dynamics Equation of the Three Game Agents}

1. The replicator dynamics equation of the central environmental protection department

Let $U_{X 1}$ represent the expected payoff of the central environmental protection department if it pursues strict regulations, and $U_{X 2}$ represent the payoff of the central environmental protection department if it does not pursue strict regulations. $U_{X}$ represents the average expected payoff of the central environmental protection department. $U_{X 1}, U_{X 2}$, and $U_{X}$ can be expressed as:

$$
\begin{gathered}
U_{X 1}=y \times z \times a_{1}+(1-y) \times z \times a_{2}+y \times(1-z) \times a_{5}+(1-y) \times(1-z) \times a_{6} \\
U_{X 2}=y \times z \times a_{3}+(1-y) \times z \times a_{4}+y \times(1-z) \times a_{7}+(1-y) \times(1-z) \times a_{8} \\
U_{X}=x \times U_{X 1}+(1-x) \times U_{X 2}
\end{gathered}
$$

Therefore, the replicator dynamics equation of the central environmental protection department can be written as:

$$
\begin{gathered}
F(x)=\frac{d x}{d t}=x \times\left(U_{X 1}-U_{X}\right) \\
=-(-1+x) x\left(W-C_{1}+C_{11}-L_{1}+L_{2}-y L_{2}-z L_{2}+y z L_{2}-z R_{3}\right)
\end{gathered}
$$

2. The replicator dynamics equation of local government officials

Let $U_{Y 1}$ represent the expected payoff of local government officials if they put emphasis on environmental issues, and $U_{Y 2}$ represent the payoff of local government officials if they neglect 
environmental issues. $U_{Y}$ represents the average expected payoff of local government officials. Then $U_{Y 1}, U_{Y 2}$, and $U_{Y}$ can be expressed as:

$$
\begin{gathered}
U_{Y 1}=x \times z \times b_{1}+x \times(1-z) \times b_{5}+(1-x) \times z \times b_{3}+(1-x) \times(1-z) \times b_{7} \\
U_{Y 2}=x \times z \times b_{2}+x \times(1-z) \times b_{6}+(1-x) \times z \times b_{4}+(1-x) \times(1-z) \times b_{8} \\
U_{Y}=y \times U_{Y 1}+(1-y) \times U_{Y 2}
\end{gathered}
$$

The replicator dynamics equation of the local government can be written as:

$$
\begin{gathered}
F(y)=\frac{d y}{d t}=y \times\left(U_{Y 1}-U_{Y}\right) \\
=(y-1) y\left(G+C_{2}-C_{22}-x L_{2}-z L_{2}+x z L_{2}-R_{2}-x R_{33}-z R_{333}+x z R_{333}\right)
\end{gathered}
$$

3. The replicator dynamics equation of the whistleblower

Let $U_{Z 1}$ represent the expected payoff of the whistleblower if he/she decides to blow the whistle, and $U_{Z 2}$ represent the expected payoff of the whistleblower if he/she decides not to blow the whistle. $U_{Z}$ represents the average expected payoff of the whistleblower. Then $U_{Z 1}, U_{Z 2}$, and $U_{Z}$ can be expressed as:

$$
\begin{gathered}
U_{Z 1}=x \times y \times c_{1}+x \times(1-y) \times c_{2}+(1-x) \times y \times c_{3}+(1-x) \times(1-y) \times c_{4} \\
U_{Z 2}=x \times y \times c_{5}+x \times(1-y) \times c_{6}+(1-x) \times y \times c_{7}+(1-x) \times(1-y) \times c_{8} \\
U_{Z}=z \times U_{Z 1}+(1-z) \times U_{Z 2}
\end{gathered}
$$

The replicator dynamics equation of the whistleblower can be written as:

$$
\begin{gathered}
F(z)=\frac{d z}{d t}=z \times\left(U_{Z 1}-U_{Z}\right) \\
=(-1+z) z\left(C_{3}-x y R_{3}+(-1+y)\left(x R_{33}-(-1+x) R_{333}\right)\right)
\end{gathered}
$$

\subsection{Stability Analysis of the Evolutionary Game}

By combining these replicator dynamics equations above, we can obtain a three-dimensional dynamic group evolution system with three agents. In this three-dimensional dynamic system, the probability of the three agents' different strategies is affected by time. The solution domain of $F(x)$, $F(y)$, and $F(z)$ is $[0,1] \times[0,1] \times[0,1]$. By letting $F(x)=0, F(y)=0, F(z)=0$, i.e., letting the rate of strategy change be zero, we can obtain the equilibrium points of this dynamic system, which are $(0,0,0),(0,0,1),(0,1,0),(1,0,0),(1,1,0),(1,0,1),(0,1,1)$, and $(1,1,1)$, respectively. These eight equilibrium points constitute the boundary of the domain of this evolutionary game, and the stability of these equilibrium points in this evolutionary system can be obtained by local stability analysis of the Jacobian matrix [57-59].

By making derivation on these three replicator dynamics equations, we can get:

$$
\begin{gathered}
F^{\prime}(x)=(1-2 x)\left(W-C_{1}+C_{11}-L_{1}+L_{2}-y L_{2}-z L_{2}+y z L_{2}-z R_{3}\right) \\
F^{\prime}(y)=-(1-2 y)\left(G+C_{2}-C_{22}-x L_{2}-z L_{2}+x z L_{2}-R_{2}-x R_{33}-z R_{333}+x z R_{333}\right) \\
F^{\prime}(z)=-(1-2 z)\left(C_{3}-x y R_{3}+(-1+y)\left(x R_{33}-(-1+x) R_{333}\right)\right)
\end{gathered}
$$

According to the characteristics of the evolutionary game, after substituting these equilibrium points into the formula above, if $F^{\prime}(x)<0, F^{\prime}(y)<0, F^{\prime}(z)<0$, it means the equilibrium strategies $x$, $y$, and $z$ respectively represent the stable strategy adopted by the three agents in the evolution process. Then we will use Wolfram Mathematica for stability analysis.

(1) Analysis of the Asymptotic Stability of the Central Environmental Protection Department 
According to Formula (5), if $W-C_{1}+C_{11}-L_{1}+L_{2}-y L_{2}-z L_{2}+y z L_{2}-z R_{3}=0$, then $F(x) \equiv 0$, indicating the boundary of the stable state. Its phase diagram is shown in Figure 3a.

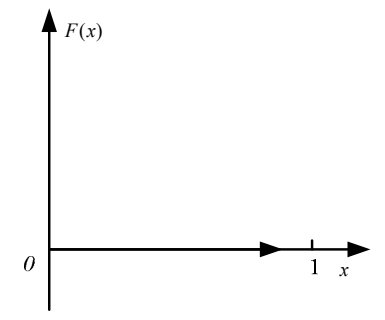

(a)

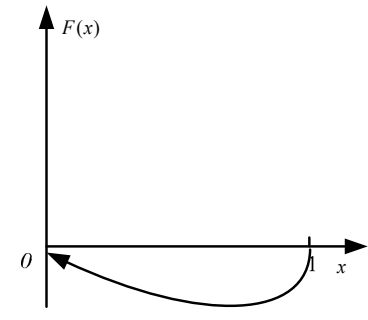

(b)

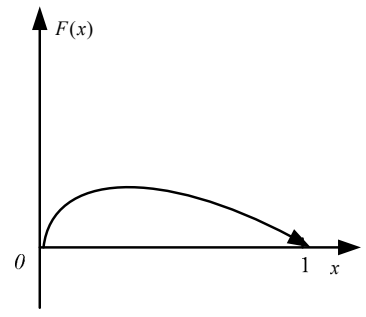

(c)

Figure 3. Replicator dynamics phase diagram of the central environmental protection department's strategy: (a) $z=\frac{W-C_{1}+C_{11}-L_{1}+L_{2}-y L_{2}}{L_{2}-y L_{2}+R_{3}} ;$ (b) $z<\frac{W-C_{1}+C_{11}-L_{1}+L_{2}-y L_{2}}{L_{2}-y L_{2}+R_{3}} ;$ (c) $z>\frac{W-C_{1}+C_{11}-L_{1}+L_{2}-y L_{2}}{L_{2}-y L_{2}+R_{3}}$.

If $W-C_{1}+C_{11}-L_{1}+L_{2}-y L_{2}-z L_{2}+y z L_{2}-z R_{3} \neq 0$, let $F(x)=0$, and we can get two stable points of $x=0$ and $x=1$. If $W-C_{1}+C_{11}-L_{1}+L_{2}-y L_{2}-z L_{2}+y z L_{2}-z R_{3}<0$, i.e., $z<\frac{W-C_{1}+C_{11}-L_{1}+L_{2}-y L_{2}}{L_{2}-y L_{2}+R_{3}}$, then $F^{\prime}(x) \mid x-0<0$ and $F^{\prime}(x) \mid x-1>0$. Therefore, $x=0$ is the stable strategy, and the central environmental protection department will decide not to pursue strict regulation. Its phase diagram is shown in Figure $3 \mathrm{~b}$. On the contrary, if $W-C_{1}+C_{11}-L_{1}+L_{2}-$ $y L_{2}-z L_{2}+y z L_{2}-z R_{3}>0$, i.e., $z>\frac{W-C_{1}+C_{11}-L_{1}+L_{2}-y L_{2}}{L_{2}-y L_{2}+R_{3}}$, then $F^{\prime}(x) \mid x-0>0$ and $F^{\prime}(x) \mid x-1<0$. Therefore, $x=1$ is the stable strategy and the central environmental protection department will decide to pursue strict regulation. Its phase diagram is shown in Figure 3c.

By combining the three cases in Figure $3 a-c$, this paper has obtained the dynamic trend and stability of the central environmental protection department's strategy in three scenarios, as shown in Figure 4.

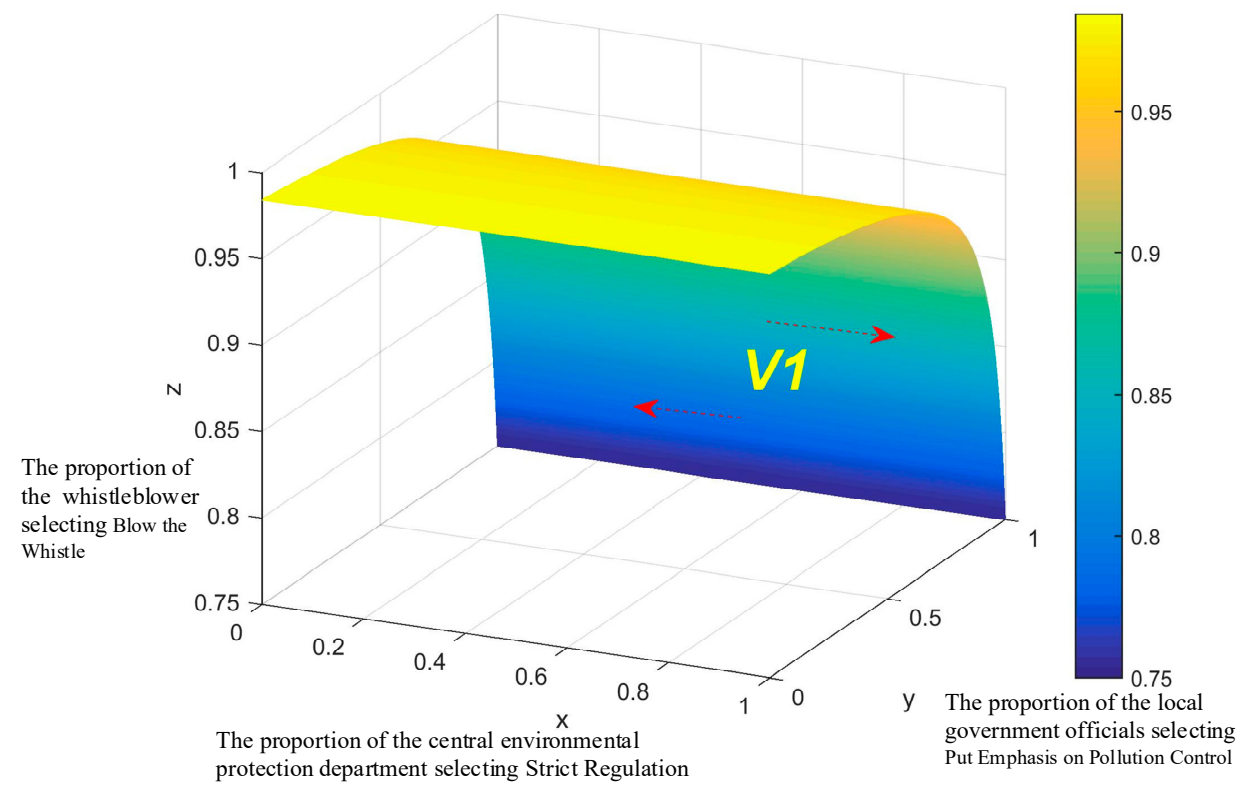

Figure 4. Dynamic trend and stability analysis of the central environmental protection department's strategy.

The eight equilibrium stable points in Figure 4 are $(0,0,0),(0,0,1),(0,1,0),(1,0,0),(1,1,0),(1,0,1)$, $(0,1,1)$, and $(1,1,1)$, respectively. These eight equilibrium points constitute the boundary of the domain of this evolutionary game. Under the constraints of $z<\frac{W-C_{1}+C_{11}-L_{1}+L_{2}-y L_{2}}{L_{2}-y L_{2}+R_{3}}$, the three-party game hybrid strategy moves to $x=0$, and we can prove that when the proportion of the whistleblower selecting Blow 
the Whistle is less than the critical value, the central environmental protection department tends to select Loose Regulation strategy. On the contrary, when the proportion of the whistleblower selecting Blow the Whistle is greater than the critical value, the central environmental protection department tends to select Strict Regulation strategy.

(2) Analysis of the Asymptotic Stability of Local Government Officials

According to the formula (9), if $G+C_{2}-C_{22}-x L_{2}-z L_{2}+x z L_{2}-R_{2}-x R_{33}-z R_{333}+x z R_{333}=$ 0 , then $F(y) \equiv 0$, indicating the boundary of the stable state. Its phase diagram is shown in Figure 5 a.

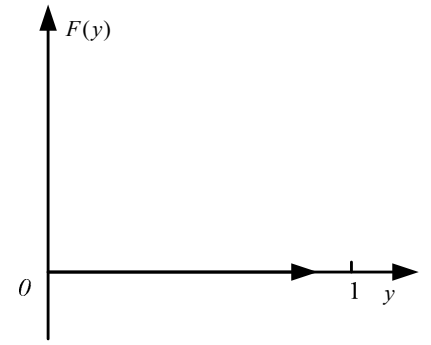

(a)

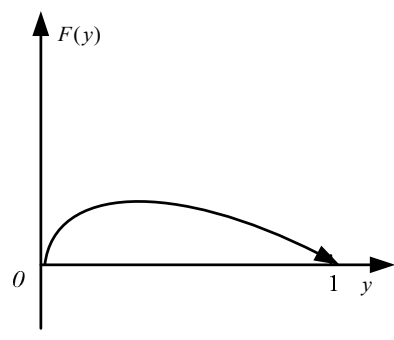

(b)

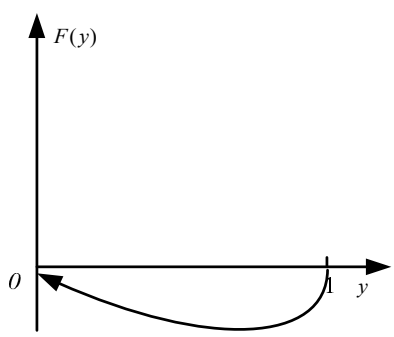

(c)

Figure 5. Replicator dynamics phase diagram of local government officials' strategy: (a) $z=$ $\frac{G+C_{2}-C_{22}-x L_{2}-R_{2}-x R_{33}}{L_{2}-x L_{2}+R_{333}-x R_{333}}$; (b) $z>\frac{G+C_{2}-C_{22}-x L_{2}-R_{2}-x R_{33}}{L_{2}-x L_{2}+R_{333}-x R_{333}}$; (c) $z<\frac{G+C_{2}-C_{22}-x L_{2}-R_{2}-x R_{33}}{L_{2}-x L_{2}+R_{333}-x R_{333}}$.

If $G+C_{2}-C_{22}-x L_{2}-z L_{2}+x z L_{2}-R_{2}-x R_{33}-z R_{333}+x z R_{333} \neq 0$, let $F(y)=0$, and we can get two stable points of $y=0$ and $y=1$. If $-\left(G+C_{2}-C_{22}-x L_{2}-z L_{2}+\right.$ $\left.x z L_{2}-R_{2}-x R_{33}-z R_{333}+x z R_{333}\right)<0$, i.e., $z>\frac{G+C_{2}-C_{22}-x L_{2}-R_{2}-x R_{33}}{L_{2}-x L_{2}+R_{333}-x R_{333}}$, then $F^{\prime}(y) \mid y-0>0$ and $F^{\prime}(y) \mid y-1<0$. Therefore, $y=1$ is the stable strategy, and the local government officials will choose to put emphasis on pollution issues. Its phase diagram is shown in Figure $5 \mathrm{~b}$. On the contrary, if $G+C_{2}-C_{22}-x L_{2}-z L_{2}+x z L_{2}-R_{2}-x R_{33}-z R_{333}+x z R_{333}>0$, i.e., $z<\frac{G+C_{2}-C_{22}-x L_{2}-R_{2}-x R_{33}}{L_{2}-x L_{2}+R_{333}-x R_{333}}$, then $F^{\prime}(y) \mid y-0<0$ and $F^{\prime}(y) \mid y-1>0$. Therefore, $y=0$ is the stable strategy and the local government officials will choose to neglect pollution issues. Its phase diagram is shown in Figure $5 c$.

By combining the three cases in Figure $5 \mathrm{a}-\mathrm{c}$, this paper has obtained the dynamic trend and stability of local government officials' strategy in three scenarios as shown in Figure 6.

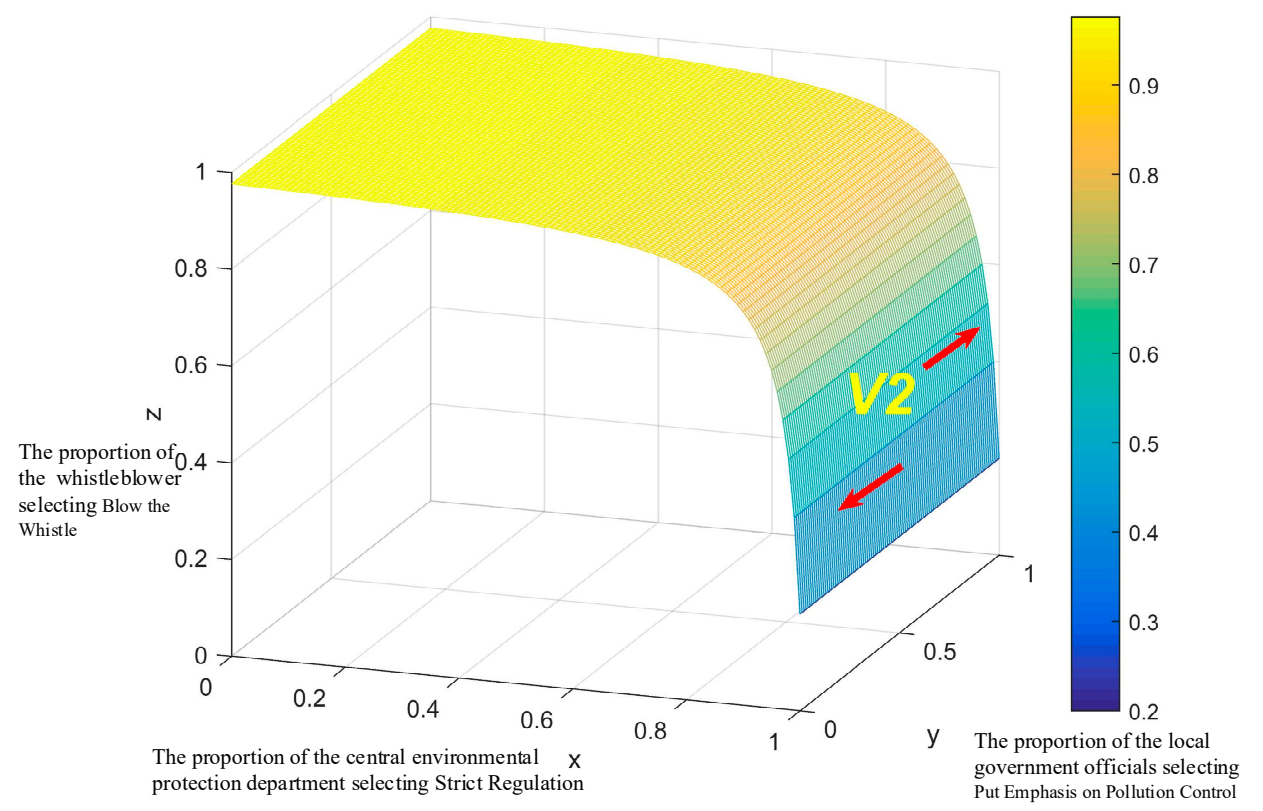

Figure 6. Dynamic trend and stability analysis of local government officials' strategy. 
The eight equilibrium stable points in Figure 6 are $(0,0,0),(0,0,1),(0,1,0),(1,0,0),(1,1,0),(1,0,1)$, $(0,1,1)$, and $(1,1,1)$, respectively. These eight equilibrium points constitute the boundary of the domain of this evolutionary game. Under the constraints of $z>\frac{G+C_{2}-C_{22}-x L_{2}-R_{2}-x R_{33}}{L_{2}-x L_{2}+R_{333}-x R_{333}}$, the three-party game hybrid strategy moves to $y=1$, and we can prove that when the proportion of the whistleblower selecting Blow the Whistle is greater than the critical value, the local government officials tend to select Put Emphasis on Pollution Control strategy. On the contrary, when the proportion of the whistleblower selecting Blow the Whistle is less than the critical value, the local government officials tend to select Neglect Pollution Control strategy.

(3) Analysis of the Asymptotic Stability of the Whistleblower

According to the formula (13), if $\left(C_{3}-x y R_{3}+(-1+y)\left(x R_{33}-(-1+x) R_{333}\right)\right)=0$, then $\mathrm{F}(\mathrm{z}) \equiv 0$, indicating the boundary of the stable state. Its phase diagram is shown in Figure $7 \mathrm{a}$.

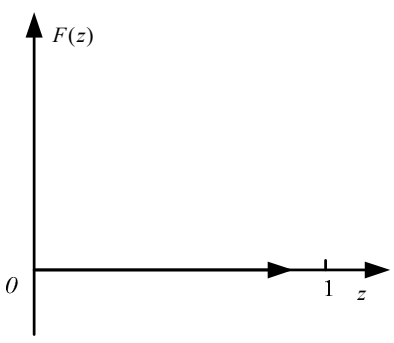

(a)

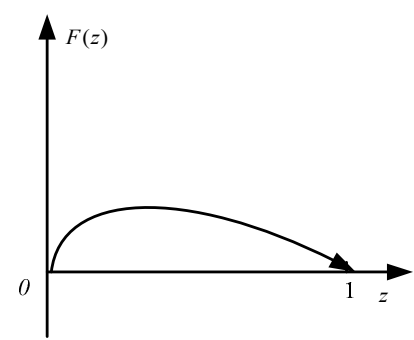

(b)

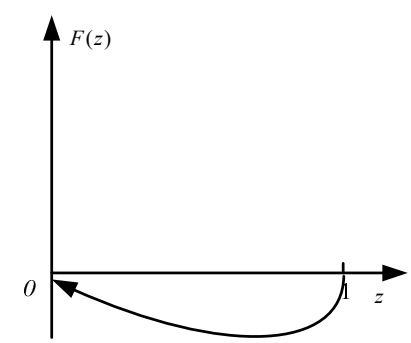

(c)

Figure 7. Replicator dynamics phase diagram of the whistleblower's strategy: (a) $x=$ $\frac{C_{3}-R_{333}+y R_{333}}{y R_{3}+R_{33}-y R_{33}-R_{333}+y R_{333}} ;$ (b) $x>\frac{C_{3}-R_{333}+y R_{333}}{y R_{3}+R_{33}-y R_{33}-R_{333}+y R_{333}} ;$ (c) $x<\frac{C_{3}-R_{333}+y R_{333}}{y R_{3}+R_{33}-y R_{33}-R_{333}+y R_{333}}$.

$\mathrm{Z}$ is constant. If $\left(C_{3}-x y R_{3}+(-1+y)\left(x R_{33}-(-1+x) R_{333}\right)\right) \neq 0$, let $F(z)=0$, and we can get two stable points of $z=0$ and $z=1$. If $-\left(C_{3}-x y R_{3}+(-1+y)\left(x R_{33}-(-1+x) R_{333}\right)\right)<0$, i.e., $x>\frac{C_{3}-R_{333}+y R_{333}}{y R_{3}+R_{33}-y R_{33}-R_{333}+y R_{333}}$, then $F^{\prime}(z) \mid z-0>0$ and $F^{\prime}(z) \mid z-1<0$. Therefore, $z=1$ is the stable strategy, and the whistleblower will decide to blow the whistle. Its phase diagram is shown in Figure $7 \mathrm{~b}$. On the contrary, if $-\left(C_{3}-x y R_{3}+(-1+y)\left(x R_{33}-(-1+x) R_{333}\right)\right)>0$, i.e., $x<\frac{C_{3}-R_{333}+y R_{333}}{y R_{3}+R_{33}-y R_{33}-R_{333}+y R_{333}}$, then $F^{\prime}(z) \mid z-0<0$ and $F^{\prime}(z) \mid z-1>0$. Therefore, $z=0$ is the stable strategy, and the whistleblower will decide not to blow the whistle. Its phase diagram is shown in Figure 7c.

By combining the three cases in Figure $7 \mathrm{a}-\mathrm{c}$, this paper has obtained the dynamic trend and stability of the whistleblower's strategy in three scenarios as shown in Figure 8.

The eight equilibrium stable points in Figure 8 are $(0,0,0),(0,0,1),(0,1,0),(1,0,0),(1,1,0),(1,0,1)$, $(0,1,1)$, and $(1,1,1)$, respectively. These eight equilibrium points constitute the boundary of the domain of this evolutionary game. Under the constraints of $x>\frac{C_{3}-R_{333}+y R_{333}}{y R_{3}+R_{33}-y R_{33}-R_{333}+y R_{333}}$, the three-party game hybrid strategy moves to $z=1$, and we can prove that when the proportion of the central environmental protection department selecting Strict Regulation is greater than the critical value, the whistleblowers tend to select Blow the Whistle strategy. On the contrary, when the proportion of the central environmental protection department selecting Strict Regulation is less than the critical value, the whistleblowers tend to select Not Blow the Whistle strategy.

In summary, when the proportion of the whistleblower selecting Blow the Whistle is greater than the critical value, the central environmental protection department tends to select Strict Regulation strategy(see Figure 4); when the proportion of the whistleblower selecting Blow the Whistle is greater than the critical value, the local government officials tend to select Put Emphasis on Pollution Control strategy (see Figure 6); when the proportion of the central environmental protection department selecting Strict Regulation is greater than the critical value, the whistleblowers tend to select Blow the Whistle strategy (see Figure 8). 


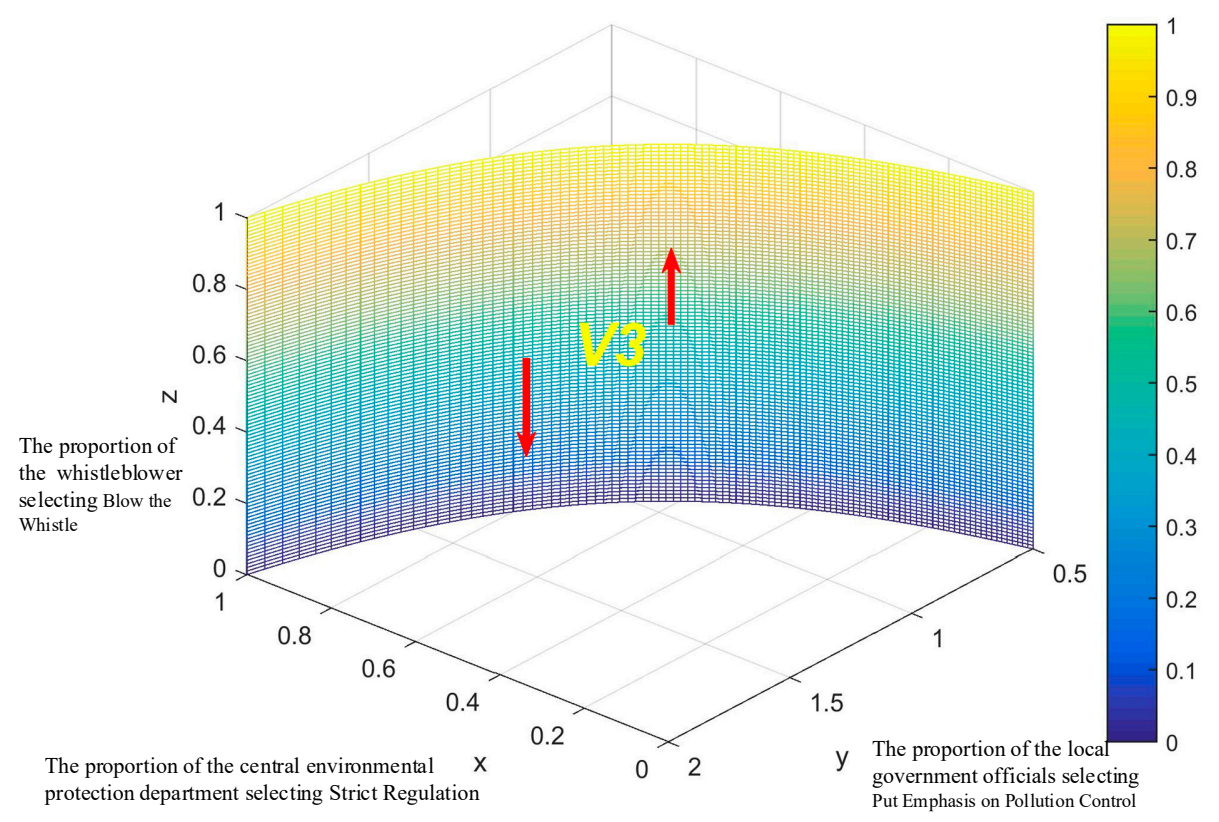

Figure 8. Dynamic trend and stability analysis of the whistleblower's strategy.

\section{Simulations and Discussions}

Based on the stability analysis of the evolutionary game, it can be seen that the evolutionary equilibrium of the central environmental protection department changes with $y$ (the probability that the local government officials put emphasis on pollution control) and $z$ (the probability that the whistleblower blows the whistle); the evolutionary equilibrium of local government officials changes with $x$ (the probability that the central environmental protection department chooses strict regulation) and $z$ (the probability that the whistleblower blows the whistle); and the evolutionary equilibrium of the whistleblower changes with $x$ (the probability that the central environmental protection department chooses strict regulation) and $y$ (the probability that the local government officials put emphasis on pollution control).

Since the values of $x, y$, and $z$ change from time to time during the evolution process, and since the equilibrium of this evolutionary game is not robust against small changes in the values of $x, y$, and $z$, we cannot make the three-party game evolve towards the expected stable equilibrium merely by adjusting the initial conditions. This paper is committed to promoting the evolution of this three-party game towards the social rational model, that is, strict regulation by the central environmental protection department, great emphasis on pollution control by local government officials, and whistleblowing by the citizens (i.e., $x=1, y=1, z=1$ ). Therefore, we could guide the behavior of different agents towards the desired direction by controlling or adjusting related variables. More specifically, this paper has conducted numerical experiments on the evolution process of the behaviors of the three parties by combining the constraints and replicator dynamic Equations (5), (9), and (13) in order to analyze the impact of changes in parameters on the evolution result. The study adopts MATLAB R2015b to simulate the evolution process for the behavior strategies.

(1) The Dynamic Evolution of Central Supervision Authorities, Local Government Officials, and Whistleblowers in the Initial State

$x_{0}, y_{0}, z_{0}$ respectively indicate the initial proportion or probability of the central environmental department choosing the "strict supervision" strategy, the local governments choosing the "emphasis on pollution control" strategy, and the whistleblowers choosing the "participation" strategy, with the initial time of 0 and evolution end time of 5. The values of the parameters are: $R_{1}=20, C_{1}=10$, $W=26.5, L_{1}=20, C_{11}=5, R_{2}=22.5, C_{2}=20, G=50, C_{22}=10, L_{2}=30, R_{3}=2, R_{3}=2, R_{33}=3, R_{333}=3.1$, 
and $C_{3}=1$. Let $x_{0}=0.1, y_{0}=0.1, z_{0}=0.1$, and the initial system simulation results are shown in Figure 9.

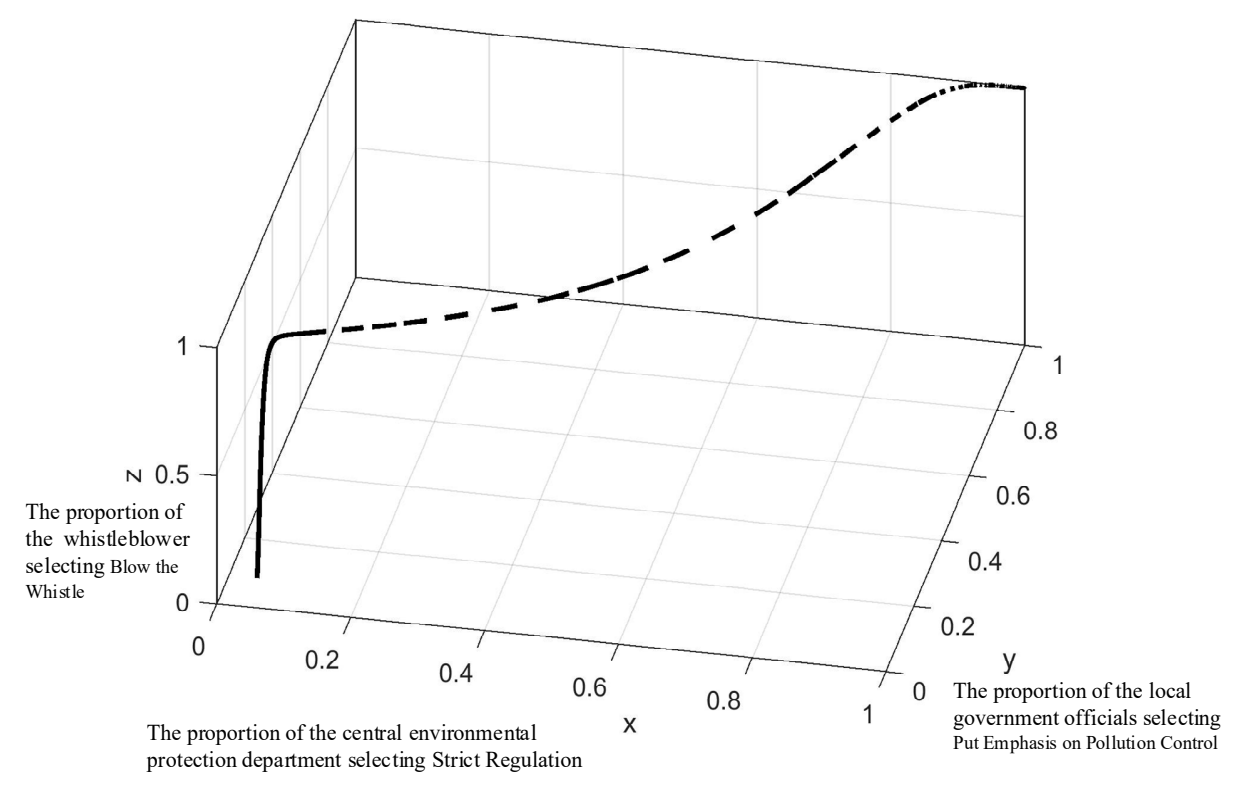

Figure 9. System evolution results in the initial state $\left(x_{0}=0.1, y_{0}=0.1, z_{0}=0.1\right)$.

The above simulation results have verified the stability of the above equilibrium points as well as the derivation of the system evolution results. The system finally reaches a stable equilibrium state $(1,1,1)$, which satisfies Assumption 4, i.e., the three-party game system adopts the mixed strategy of strict supervision by the central environmental department, emphasis on pollution control by the local governments, and active participation and reporting by the whistleblowers.

Furthermore, through the simulation experiments with different changes to the initial state, this paper has obtained the impacts of initial state change on the evolution result when all other parameters are unchanged. The results of the simulation experiments with initial state change are shown in Figure 9.

As shown in the simulation results comparison, the initial state of the three-party game agents has significant impact on the evolution of the game system towards the stable equilibrium state. The higher the initial $x, y, z$ are, the shorter time it takes for the system to reach the stable equilibrium state. When $(x, y, z)$, (i.e., strict regulation, emphasis on pollution control, participation in whistleblowing) take the strategy proportions of $(0.2,0.3,0.4)$, the game system will reach the stable equilibrium state at around $t=3$. When the proportions increase to $(0.5,0.6,0.7)$, the game system will reach the stable equilibrium state at around $t=2.5$. When the proportions increase to $(0.8,0.8,0.8)$, the game system will reach the stable equilibrium state at around $t=1.5$. This indicates that the increase in initial state proportions would help shorten the time it takes for the game system to evolve to the stable equilibrium state, that is, increasing the proportion of strategy choices of (strict regulation, emphasis on pollution control, participation in whistleblowing) by the game agents would help facilitate pollution control.

Furthermore, it is shown by Figure 9 that as long as the central supervision department increases the probability of strict supervision, it can indirectly increase the incentive probability, thus greatly enhancing the enthusiasm of whistleblowers and quickly reaching the equilibrium state of the whistleblowers. However, when the initial state is comparatively low $\left(x_{0}=0.1, y_{0}=0.1, z_{0}=0.1\right)$, the local governments do not put much emphasis on pollution control, and the increase in whistleblowing probability cannot enhance local governments' emphasis on the environment. With the increase in the probability of strict supervision by the central supervision department, the local government officials would greatly raise their emphasis on environmental pollution $(y>0.8008)$ when there is a high probability of strict supervision by the central supervision department $(x>0.8017)$, and would 
evolve towards the equilibrium state $(0.9934,0.9999,0.9997)$. The initial stage of environmental pollution control in China is a relatively low initial state. First, the central supervision department needs to increase the probability of strict supervision, and then local governments need to raise their emphasis on pollution control, and the whistleblowers should also be encouraged to participate in environmental whistleblowing. Only when the three parties increase their environmental awareness $\left(x>x_{0}, y>y_{0}, z>z_{0}\right)$, can the environmental pollution issues be efficiently managed and controlled.

(2) The Dynamic Evolution of Central Supervision Authorities, Local Government Officials, and Whistleblowers under Different Parameters

Based on the stability analysis of the evolutionary game, it can be seen that a number of influencing factors also have a great impact on the evolution of the system.

When $z>\frac{W-C_{1}+C_{1}-L_{1}+L_{2}-y L_{2}}{L_{2}-y L_{2}+R_{3}}, x \rightarrow 1$, which means the central environmental protection department would eventually choose strict regulation. Therefore, by increasing the penalty on local government officials who neglect pollution control $\left(L_{2}\right)$ and increasing the rewards to whistleblowers $\left(R_{3}\right)$, we could encourage the central environmental protection department to evolve towards the strategy of strict regulations.

When $z>\frac{G+C_{2}-C_{22}-x L_{2}-R_{2}-x R_{33}}{L_{2}-x L_{2}+R_{333}-x R_{333}}, y \rightarrow 1$, which means local government officials would eventually put an emphasis on pollution control. Therefore, by raising the compensation to whistleblowers by local government officials who neglect pollution control $\left(R_{33}\right)$, lowering the pollution control cost of local governments $\left(C_{2}\right)$, enhancing the role of reputation and public opinion in political career or official promotion $\left(R_{2}\right)$, increasing the penalty on local government officials who neglect pollution control $\left(L_{2}\right)$ as well as the cost on local government officials if they neglect pollution control $\left(C_{22}\right)$, and to some extent making it more difficult for local government officials to use measures such as "hush money" to call off whistleblowing (i.e., lowering $R_{333}$ ), we could also motivate local government officials to evolve towards the strategy of emphasizing pollution control and environmental issues.

When $y>\frac{-C_{3}+x R_{33}+R_{333}-x R_{333}}{-x R_{3}+x R_{33}+R_{333}-x R_{333}}=1-\frac{x R_{3}-C_{3}}{\left(R_{3}-R_{33}+R_{333}\right) x-R_{333}}, z \rightarrow 1$, which means the whistleblower would eventually decide to blow the whistle. Therefore, by increasing the rewards to whistleblowers by the central environmental protection department $\left(R_{3}\right)$, lowering the cost of whistleblowing $\left(C_{3}\right)$, raising the compensation to whistleblowers by local government officials who neglect pollution control $\left(R_{33}\right)$, and to some extent making it more difficult for local government officials to use measures such as "hush money" to call off whistleblowing (i.e., lowering $R_{333}$ ), we could encourage whistleblowers to evolve towards the strategy of blowing the whistle.

Therefore, we could select multiple factors to analyze the impact of parameter change on the evolution result. While keeping all other parameters and the low-level initial state of ( $x_{0}=0.1, y_{0}=0.1, z_{0}=0.1$ ) unchanged, the results of the simulation experiments where the central environmental protection department strengthens punishment on local governments that neglect air pollution issues and lowers the cost of whistleblowing are shown in Figure 10.

The simulation results indicate that by strengthening the punishment on local governments that neglect air pollution issues and lowering the cost of whistleblowing, the central environmental protection department could significantly enhance the local government officials' attention to environmental pollution and facilitate the local governments' strategy to evolve towards the stable equilibrium. Moreover, in the long term, this could also effectively reduce central supervision departments' regulatory cost on local governments and achieve the strategy of emphasis on pollution control by the local governments and active participation by the whistleblowers with a comparatively lower probability of strict supervision.

In the same way, the impact of other parameter changes that are conducive to pollution control, such as increasing the weight of public opinion in local government officials' performance evaluation and promotion, reducing the pollution control costs of local governments, improving the rewards to whistleblowers, and enhancing the compensation from the government to whistleblowers, could also be experimented with the above method. Due to space limitations, this paper will not elaborate further. There are two important factors that affect the speed at which the three-party game system 
reaches the evolutionary stability strategy (ESS). One is the initial probability. The larger the initial probability, the faster the system reaches the ESS (see Figure 10). The other is the magnitude of penalties, incentives, and environmental governance costs. It is necessary to reduce the cost of pollution control by local government and the cost of whistleblowers, based on increasing the magnitude of penalties to local governments' negative response to environmental protection and the effective reports from whistleblowers (see Figure 11).

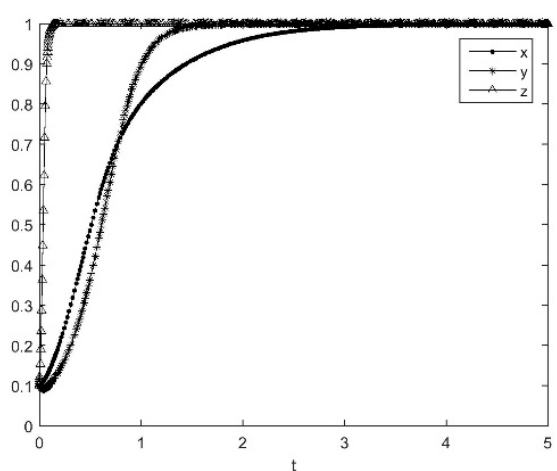

(a)

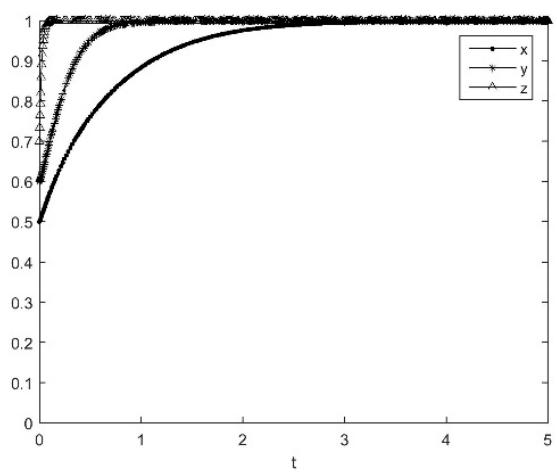

(c)

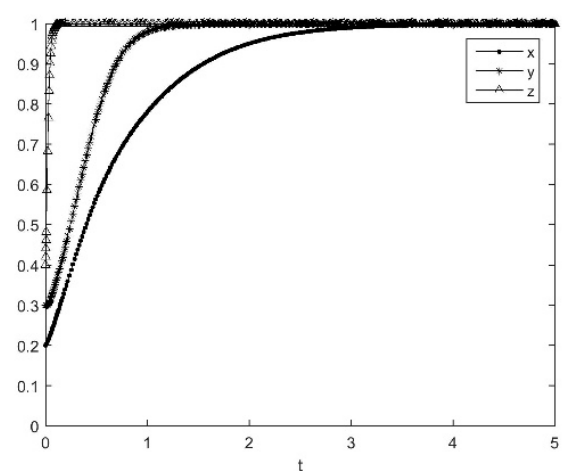

(b)

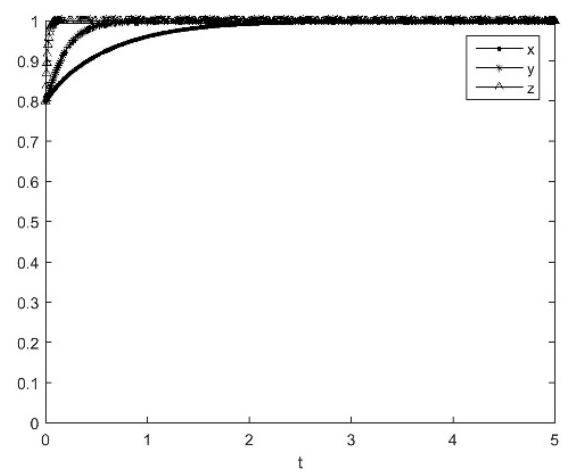

(d)

Figure 10. The effect of state changes on system evolution results: (a) $x_{0}=0.1, y_{0}=0.1, z_{0}=0.1$; (b) $x_{0}=0.2, y_{0}=0.3, z_{0}=0.5 ;$ (c) $x_{0}=0.5, y_{0}=0.6, z_{0}=0.7$; (d) $x_{0}=0.8, y_{0}=0.8, z_{0}=0.8$.

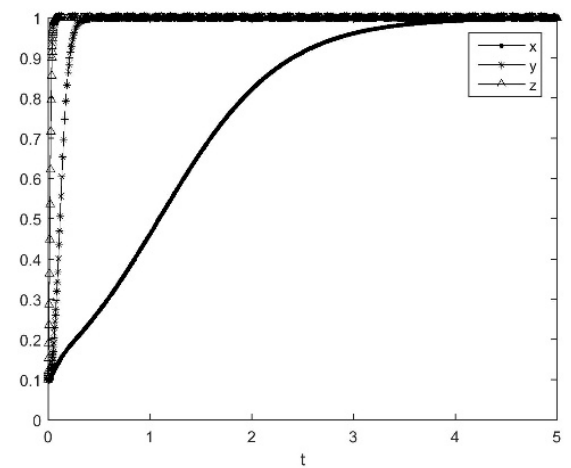

(a)

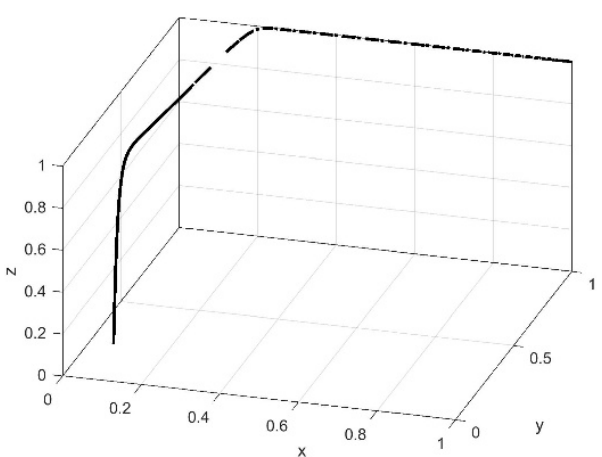

(b)

Figure 11. Effect of parameter changes on system evolution results from the initial state $\left(x_{0}=0.1\right.$, $y_{0}=0.1, z_{0}=0.1$ ): (a) two-dimensional diagram of the result; (b) three-dimensional diagram of the result.

It is worth noting that as indicated by the simulation results, the reward to whistleblowers can urge local governments to raise their emphasis on environmental pollution control and management 
to some extent; however, from the sustainability perspective, when the emphasis on environmental pollution is generally low, the supervision and punishment of the central supervision department plays a crucial role, and reducing the pollution control costs of the local governments can achieve the same effect as punishment, such as increasing the central government's subsidies to environmental pollution control, setting the environmental quality as one performance indicator in local governments' performance evaluation, etc.

\section{Conclusions}

This paper has focused on the three main parties involved in environmental pollution control-the central supervision department, local governments, and whistleblowers-and constructed a three-party evolutionary game model based on evolutionary game theory. This paper has also analyzed the equilibrium points as well as the evolutionary stable strategy in the three-dimensional dynamic system using the replicator dynamics equation. This paper has then conducted numerical simulations to demonstrate the impact of different values on the evolution result of environmental pollution control. The results of this study indicate that the positive feedback among behaviors of the central supervision department, local government officials, and the whistleblowers can facilitate the improvement in environmental awareness of the entire society, enhance environmental pollution control, and promote the harmonious coexistence of human society and nature. Based on the above conclusions, this paper has provided the following recommendations for further improvement of China's environmental pollution control:

(1) Public participation is an indispensable part of environmental pollution control and one of the fundamental ways to solve environmental problems [60,61]. It is suggested that whistleblowing be encouraged by reducing the whistleblowing cost and increasing the reward to a certain level [53]. The traditional whistleblowing channels (such as petitioning and hotlines) have high time and economic costs and low efficiency, while the rapid development of the Internet and smart phones has offered new methods with comparatively low economic costs. Therefore, we should make full use of low cost online channels, such as WeChat, Weibo, and other online platforms to encourage whistleblowing. The convenient online channels could effectively enhance the interactions between whistleblowers and the Ministry of Environmental Protection, and indirectly increase the rewards for whistleblowing while saving time and economic costs.

(2) It is necessary to further increase the punishment on local government officials that neglect pollution control and use subsidies to lessen the concern of local government officials on pollution control costs. It is recommended that "promotion" be used as an incentive for local government officials, and to comprehensively evaluate government officials' political achievements from multiple aspects including local economic indicators and environmental indicators. We should not only supervise local government officials' emphasis on local environmental pollution control, but also conduct spot checks on the achievements of pollution control with reference to whistleblowers' feedback. Compared with developed countries, currently the local air pollution control performance in China does not have much weight in the promotion of local government officials $[62,63]$. In future policy design, it is recommended that bonus points be given to local government officials that work hard on environment improvement and air pollution control in promotion evaluation, or lower the requirements on economic indicators in performance assessment. At the same time, the central environmental protection department should provide proper and reasonable subsidies based on the local policy and measures targeting air pollution according to the actual situation.

(3) Establish and improve the disclosure system for air pollution information and supervision progress. The public disclosure of air pollution information is a new environment management method different from the "administrative control measures" and "market economy measures" [64,65]. It could put pressure on the polluters and environmental departments by disclosing relevant environmental information and utilizing public opinion, thus urging them to change their behavior with help of public supervision in order to eventually achieve the goal of environmental protection. The central 
supervision department should make efforts to properly collect and disclose the whistleblowing data from different regions related to environmental pollution. It should not only publicly disclose relevant information such as the number of whistleblowing cases in different regions, but also urge various local governments to establish and improve air pollution information disclosure and supervision progress disclosure systems as soon as possible, in order to form a positive trend in which various parties actively and efficiently participate in air pollution control.

Author Contributions: Y.Y. and W.Y. are joint first authors. They contributed equally to this paper. Conceptualization, W.Y.; Methodology, Y.Y. and W.Y.; Resources, Y.Y. and W.Y.; Software, Y.Y.; Validation, W.Y.; Formal Analysis, Y.Y. and W.Y.; Data Curation, Y.Y. and W.Y.; Writing-Original Draft Preparation, Y.Y. and W.Y.; Writing-Review and Editing, Y.Y. and W.Y.

Funding: This research was funded by the Humanities and Social Sciences Research Fund of the University of Shanghai for Science and Technology, and the Decision-making Consultation Research Project of Shanghai Municipal Government. We gratefully acknowledge the above financial supports.

Conflicts of Interest: The authors declare no conflicts of interest.

\section{References}

1. Yang, W.X.; Li, L.G. Energy Efficiency, Ownership Structure, and Sustainable Development: Evidence from China. Sustainability 2017, 9, 912. [CrossRef]

2. Yang, W.; Li, L. Analysis of Total Factor Efficiency of Water Resource and Energy in China: A Study Based on DEA-SBM Model. Sustainability 2017, 9, 1316. [CrossRef]

3. Zhai, B.; Chen, J.; Yin, W.; Huang, Z. Relevance Analysis on the Variety Characteristics of PM2.5 Concentrations in Beijing, China. Sustainability 2018, 10, 3228. [CrossRef]

4. Li, L.G.; Yang, W.X. Total Factor Efficiency Study on China's Industrial Coal Input and Wastewater Control with Dual Target Variables. Sustainability 2018, 10, 2121. [CrossRef]

5. Huang, W.; Wang, H.; Wei, Y. Endogenous or Exogenous? Examining Trans-Boundary Air Pollution by Using the Air Quality Index (AQI): A Case Study of 30 Provinces and Autonomous Regions in China. Sustainability 2018, 10, 4220. [CrossRef]

6. Liu, R.; Liu, X.; Pan, B.; Zhu, H.; Yuan, Z.; Lu, Y. Willingness to Pay for Improved Air Quality and Influencing Factors among Manufacturing Workers in Nanchang, China. Sustainability 2018, 10, 1613. [CrossRef]

7. Wang, F.; Wang, K. Assessing the Effect of Eco-City Practices on Urban Sustainability Using an Extended Ecological Footprint Model: A Case Study in Xi'an, China. Sustainability 2017, 9, 1591. [CrossRef]

8. Yang, W.; Li, L. Efficiency evaluation of industrial waste gas control in China: A study based on data envelopment analysis (DEA) model. J. Clean. Prod. 2018, 179, 1-11. [CrossRef]

9. Standing Committee of the Twelfth National people's Congress of the people's Republic of China. The Environmental Protection Law of the People's Republic of China; The Law Press of China: Beijing, China, 2014.

10. Ministry of Environmental Protection of the People's Republic of China. The Ministry of Environmental Protection Will Open the "010-12369" Environmental Whistleblowing Hotline on the World Environment Day (5 June). Available online: http:/ /www.mee.gov.cn/gkml/sthjbgw/qt/200910/t20091023_179602.htm (accessed on 17 November 2018).

11. Ministry of Environmental Protection of the People's Republic of China. The "Green Knight" Environmental Snapshot APP for Smartphone Is Officially Released. Available online: http://www.mee.gov.cn/xxgk/ hjyw /201406/t20140623_277270.shtml (accessed on 17 November 2018).

12. Ministry of Environmental Protection of the People's Republic of China. The "12369 Environment Whistleblowing Platform" on WeChat Has Been Working Well Since Its Opening in 2015. Available online: http://www.mee.gov.cn/gkml/sthjbgw/qt/201603/t20160322_334063.htm (accessed on 17 November 2018).

13. Ministry of Environmental Protection of the People's Republic of China. Report on the "12369" Environment Whistleblowing in 2016. Available online: http:/ / www.mee.gov.cn/gkml/hbb/bgth/201705/t20170512_ 414013.htm (accessed on 17 November 2018).

14. China Environment News. Strictly Supervising and Promoting the Coordinated Development of China's Environment and Economy. Available online: http:/ /www.cenews.com.cn/opinion/hjsp/201710/ t20171013_854057.html (accessed on 17 November 2018). 
15. Environmental Emergency and Accident Investigation Center of the Ministry of Environmental Protection. 12369: Promoting Environmental Information Disclosure and Public Participation. World Environ. 2017, 4, 76-77.

16. Ministry of Environmental Protection of the People's Republic of China. Report on the "12369" Environment Whistleblowing in 2017. Available online: http:/ / www.mee.gov.cn/gkml/sthjbgw / qt/201801/t20180123_ 430188.htm (accessed on 17 November 2018).

17. Wei, J.; Lu, S. Investigation and penalty on major industrial accidents in China: The influence of environmental pressures. Saf. Sci. 2015, 76, 32-41. [CrossRef]

18. Zhang, B.; Chen, X.; Guo, H. Does central supervision enhance local environmental enforcement? Quasi-experimental evidence from China. J. Public Econ. 2018, 164, 70-90. [CrossRef]

19. Chen, H.; Hao, Y.; Li, J.; Song, X. The impact of environmental regulation, shadow economy, and corruption on environmental quality: Theory and empirical evidence from China. J. Clean. Prod. 2018, 195, 200-214. [CrossRef]

20. Xinhua Net. 300,000 Yuan! A Domestic Reward Record Has Been Created for Environmental Whistleblowing in Jingjiang, Jiangsu Province. Available online: http://www.xinhuanet.com//legal/2017-11/18/c_ 1121974431.htm (accessed on 17 November 2018).

21. Zhang, Y. Rewarding Pollution Whistleblowing Highlights Environmental Protection. Environ. Prot. Circ. Econ. 2017, 37, 1.

22. Huang, G. A Number of Major Environmental Protection Cases were Uncovered by Reward for Whistleblowing. Pestic. Mark. News 2018, 11, 16-17.

23. Du, T. "Environmental Guardian” Was Arrested Twice-Suspected of Retaliation for Whistleblowing. Available online: http://www.mzyfz.com/index.php/cms/item-view-id-1199432 (accessed on 17 November 2018).

24. The Paper News. The Polluted Enterprises Retaliated the Resident after His Whistleblowing to the Central Environmental Protection Inspectorate. Available online: https:/ / www.thepaper.cn/newsDetail_forward_ 1512811 (accessed on 17 November 2018).

25. Jin, J.; Zhuang, J.; Zhao, Q. Supervision after Certification: An Evolutionary Game Analysis for Chinese Environmental Labeled Enterprises. Sustainability 2018, 10, 1494. [CrossRef]

26. Zhao, X.; Zhang, Y. The System Dynamics (SD) Analysis of the Government and Power Producers' Evolutionary Game Strategies Based on Carbon Trading (CT) Mechanism: A Case of China. Sustainability 2018, 10, 1150. [CrossRef]

27. Gao, L.; Zhao, Z.-Y. System Dynamics Analysis of Evolutionary Game Strategies between the Government and Investors Based on New Energy Power Construction Public-Private-Partnership (PPP) Project. Sustainability 2018, 10, 2533. [CrossRef]

28. Liu, L.; Feng, C.; Zhang, H.; Zhang, X. Game Analysis and Simulation of the River Basin Sustainable Development Strategy Integrating Water Emission Trading. Sustainability 2015, 7, 4952-4972. [CrossRef]

29. Zhao, R.; Zhou, X.; Han, J.; Liu, C. For the sustainable performance of the carbon reduction labeling policies under an evolutionary game simulation. Technol. Forecast. Soc. Chang. 2016, 112, 262-274. [CrossRef]

30. Wu, B.; Liu, P.; Xu, X. An evolutionary analysis of low-carbon strategies based on the government-enterprise game in the complex network context. J. Clean. Prod. 2017, 141, 168-179. [CrossRef]

31. Li, Q.; Bao, H.; Peng, Y.; Wang, H.; Zhang, X. The Collective Strategies of Major Stakeholders in Land Expropriation: A Tripartite Game Analysis of Central Government, Local Governments, and Land-Lost Farmers. Sustainability 2017, 9, 648. [CrossRef]

32. Chen, S. An Evolutionary Game Study of an Ecological Industry Chain Based on Multi-Agent Simulation: A Case Study of the Poyang Lake Eco-Economic Zone. Sustainability 2017, 9, 1165. [CrossRef]

33. Zhang, M.; Li, H. New evolutionary game model of the regional governance of haze pollution in China. Appl. Math. Model. 2018, 63, 577-590. [CrossRef]

34. Standing Committee of the Twelfth National people's Congress of the people's Republic of China. Law of the People's Republic of China on Air Pollution Prevention and Control (Latest Revision); The Law Press of China: Beijing, China, 2018.

35. State Council of the People's Republic of China. Notice of the State Council on Printing and Dispatching the Air Pollution Prevention and Control Action Plan. Available online: http:/ /www.gov.cn/zhengce/content/ 2013-09/13/content_4561.htm (accessed on 17 November 2018). 
36. Ministry of Ecology and Environment of the People's Republic of China. The Responsibility of the Ministry of Ecology and Environment of the People's Republic of China. Available online: http:/ /www.mee.gov.cn/ zjhb / zyzz/ (accessed on 17 November2018).

37. Shen, X.; Wang, L.; Wu, C.; Lv, T.; Lu, Z.; Luo, W.; Li, G. Local interests or centralized targets? How China's local government implements the farmland policy of Requisition-Compensation Balance. Land Use Policy 2017, 67, 716-724. [CrossRef]

38. Yang, W.; Li, L. Efficiency Evaluation and Policy Analysis of Industrial Wastewater Control in China. Energies 2017, 10, 1201. [CrossRef]

39. Wang, D.; Chen, C.; Richards, D. A prioritization-based analysis of local open government data portals: A case study of Chinese province-level governments. Gov. Inf. Q. 2018, 35, 644-656. [CrossRef]

40. Cao, R.; Zhang, A.; Wen, L. Trans-regional compensation mechanism under imbalanced land development: From the local government economic welfare perspective. Habitat Int. 2018, 77, 56-63. [CrossRef]

41. Zhang, L.; Wu, B. Farmer innovation system and government intervention: An empirical study of straw utilisation technology development and diffusion in China. J. Clean. Prod. 2018, 188, 698-707. [CrossRef]

42. Zhou, Y.; Zhu, S.; He, C. How do environmental regulations affect industrial dynamics? Evidence from China's pollution-intensive industries. Habitat Int. 2017, 60, 10-18. [CrossRef]

43. Cull, R.; Xu, L.C.; Yang, X.; Zhou, L.-A.; Zhu, T. Market facilitation by local government and firm efficiency: Evidence from China. J. Corp. Financ. 2017, 42, 460-480. [CrossRef]

44. Wu, J.; Xu, M.; Zhang, P. The impacts of governmental performance assessment policy and citizen participation on improving environmental performance across Chinese provinces. J. Clean. Prod. 2018, 184, 227-238. [CrossRef]

45. Geall, S.; Shen, W. Gongbuzeren Solar energy for poverty alleviation in China: State ambitions, bureaucratic interests, and local realities. Energy Res. Soc. Sci. 2018, 41, 238-248. [CrossRef]

46. Yang, Y.; Yu, G. The analysis of social resource mobilization on new media: A case study of Chinese environmental protection documentary Under the Dome. Telematics Inform. 2018. [CrossRef]

47. Shen, L.; Wang, Y. Supervision mechanism for pollution behavior of Chinese enterprises based on haze governance. J. Clean. Prod. 2018, 197, 571-582. [CrossRef]

48. Guttman, D.; Young, O.; Jing, Y.; Bramble, B.; Bu, M.; Chen, C.; Furst, K.; Hu, T.; Li, Y.; Logan, K.; et al. Environmental governance in China: Interactions between the state and "nonstate actors". J. Environ. Manag. 2018, 220, 126-135. [CrossRef] [PubMed]

49. Deng, J. The National Supervision Commission: A New Anti-corruption Model in China. Int. J. Law Crime Justice 2018, 52, 58-73. [CrossRef]

50. Liu, L.; Wu, T.; Li, S.; de Jong, M.; Sun, Y. The drivers of local environmental policy in China: An analysis of Shenzhen's environmental performance management system, 2007-2015. J. Clean. Prod. 2017, 165, 656-666. [CrossRef]

51. Zhang, L.; An, Y. The government capacity on industrial pollution management in Shanxi province: A response impulse analysis. J. Environ. Manag. 2018, 223, 1037-1046. [CrossRef]

52. Jia, S.; Liu, X.; Yan, G. Effect of APCF policy on the haze pollution in China: A system dynamics approach. Energy Policy 2019, 125, 33-44. [CrossRef]

53. Wang, L. Research on Environmental Right of Reporting and Its Protection in China. Master's Thesis, Soochow University, Suzhou, China, 2017.

54. Zhang, H.; Xiong, L.; Qiu, Y.; Zhou, D. How Have Political Incentives for Local Officials Reduced the Environmental Pollution of Resource-depleted Cities? Energy Procedia 2017, 143, 873-879. [CrossRef]

55. Yang, J.; Zhang, B. Air pollution and healthcare expenditure: Implication for the benefit of air pollution control in China. Environ. Int. 2018, 120, 443-455. [CrossRef]

56. Xia, Q.; Jin, M.; Wu, H.; Yang, C. A DEA-based decision framework to determine the subsidy rate of emission reduction for local government. J. Clean. Prod. 2018, 202, 846-852. [CrossRef]

57. Zhao, X.-G.; Ren, L.Z.; Zhang, Y.Z.; Wan, G. Evolutionary game analysis on the behavior strategies of power producers in renewable portfolio standard. Energy 2018, 162, 505-516. [CrossRef]

58. Chen, Y.; Ding, S.; Zheng, H.; Zhang, Y.; Yang, S. Exploring diffusion strategies for mHealth promotion using evolutionary game model. Appl. Math. Comput. 2018, 336, 148-161. [CrossRef] 
59. Vigliassi, M.P.; Massignan, J.A.D.; Delbem, A.C.B.; London, J.B.A. Multi-objective evolutionary algorithm in tables for placement of SCADA and PMU considering the concept of Pareto Frontier. Int. J. Electr. Power Energy Syst. 2019, 106, 373-382. [CrossRef]

60. Rollason, E.; Bracken, L.J.; Hardy, R.J.; Large, A.R.G. Evaluating the success of public participation in integrated catchment management. J. Environ. Manag. 2018, 228, 267-278. [CrossRef]

61. Brombal, D.; Moriggi, A.; Marcomini, A. Evaluating public participation in Chinese EIA. An integrated Public Participation Index and its application to the case of the New Beijing Airport. Environ. Impact Assess. Rev. 2017, 62, 49-60. [CrossRef]

62. Pu, Z.; Fu, J. Economic growth, environmental sustainability and China mayors' promotion. J. Clean. Prod. 2018, 172, 454-465. [CrossRef]

63. Taylor, C.M.; Gallagher, E.A.; Pollard, S.J.T.; Rocks, S.A.; Smith, H.M.; Leinster, P.; Angus, A.J. Environmental regulation in transition: Policy officials' views of regulatory instruments and their mapping to environmental risks. Sci. Total Environ. 2019, 646, 811-820. [CrossRef]

64. Tian, X.-L.; Guo, Q.-G.; Han, C.; Ahmad, N. Different extent of environmental information disclosure across chinese cities: Contributing factors and correlation with local pollution. Glob. Environ. Chang. 2016, 39, 244-257. [CrossRef]

65. Kasim, M.T. Evaluating the effectiveness of an environmental disclosure policy: An application to New South Wales. Resour. Energy Econ. 2017, 49, 113-131. [CrossRef]

(C) 2019 by the authors. Licensee MDPI, Basel, Switzerland. This article is an open access article distributed under the terms and conditions of the Creative Commons Attribution (CC BY) license (http://creativecommons.org/licenses/by/4.0/). 